\title{
UM ESTUDO DE CASO DO PLANEJAMENTO ESTRATÉGICO DO IFB
}

\author{
ESTUDIO DE CASO DE PLANIFICACIÓN ESTRATÉGICA DE IFB
}

A CASE STUDY OF STRATEGIC PLANNING IFB

\author{
Pedro Henrique Rodrigues de CAMARGO DIAS ${ }^{1}$ \\ Jonilto COSTA SOUSA ${ }^{2}$ \\ Jabson CAVALCANTE DIAS ${ }^{3}$
}

RESUMO: O artigo tem por objetivo identificar e caracterizar a etapa inicial de elaboração do planejamento estratégico do IFB, a partir da percepção da alta administração e equipe de planejamento. $\mathrm{O}$ estudo de caso adota uma abordagem qualitativa apoiada em técnicas de pesquisa bibliográfica, para construção de embasamento teórico, aliada à entrevista semiestruturada para posterior aplicação da análise de conteúdo. Como resultado, pode-se identificar que a instituição optou em realizar primeiramente a definição dos referencias estratégicos, a partir da construção da missão, visão e valores, e posteriormente, análise do diagnóstico organizacional, fundamentada na metodologia do Balanced Scorecard. Constatou-se que a ferramenta de planejamento estratégico e sua utilização são pontos que necessitam ser melhores compreendidos pelos gestores e equipe técnica de planejamento. As características predominantes do planejamento estratégico compõem-se de uma ferramenta programática de projeção de metas e ações de médio e longo prazo, de cumprimento legal, visto que integra e operacionaliza o Plano de Desenvolvimento Institucional - PDI.

PALAVRAS-CHAVE: Planejamento. Estratégia. Instituição. Educação. Brasil.

RESUMEN: El documento tiene como objetivo identificar y caracterizar la etapa inicial de la preparación de la planificación estratégica de la IFB, desde la percepción de la alta dirección y equipo de planificación. El estudio de caso adopta un enfoque cualitativo apoyado por técnicas de la literatura para la construcción de base teórica, combinado con entrevista semiestrutura más adelante, la aplicación de análisis de contenido. Como resultado, podemos identificar que la institución fue elegido en primer realizar la definición de las referencias estratégicas, desde el edificio de la misión, visión y valores, y posteriormente el análisis de diagnóstico organizacional, basado en la metodología Balanced Scorecard. Se encontró que una herramienta de planificación estratégica y su uso son puntos que necesitan ser mejor comprendidos por los gerentes y planificación del

\footnotetext{
1 Universidade de Brasília (UnB), Brasília - DF - Brasil. Analista de Planejamento e Orçamento do Ministério Público Federal. Mestre em Gestão Pública. E-mail: pedrohcamargo@ hotmail.com.

${ }^{2}$ Universidade de Brasília (UnB), Brasília - DF - Brasil. Professor Adjunto na Universidade de Brasília no campus de Planaltina (FUP/UnB). Doutorado em Administração. E-mail: jonilto@ hotmail.com.

${ }^{3}$ Instituto Federal de Brasília (Ifb), Brasília - DF - Brasil. Assistente em Administração do Instituto Federal de Brasília. Especialização Lato Sensu em Gestão Pública. E-mail: jabsondias@ifb.edu.br.
} 
personal técnico. Las características predominantes de la planificación estratégica, consisten en una programáticas objetivos y acciones de mediano y largo plazo, el cumplimiento legal de proyección de la herramienta, ya que, integra y opera el Plan de Desarrollo Institucional - PDI.

PALABRAS CLAVE: Planificación. Estrategia. Institución. Educación. Brasil.

ABSTRACT: The purpose of this article is to identify and characterize the initial stage of the IFB strategic planning, based on the perception of top management and planning team. The case study adopts a qualitative approach supported by bibliographic research techniques, to build a theoretical foundation, allied to the semistructure interview for later, application of the content analysis. As a result, we can identify that the institution opted to first define the strategic references, based on the construction of the mission, vision and values, and later, analysis of the organizational diagnosis, based on the Balanced Scorecard methodology. It was verified that the tool of strategic planning and its use are points that need to be better understood by the managers and technical planning team. The predominant characteristics of strategic planning are composed of a programmatic tool for projecting medium and long term goals and actions, of legal compliance, as it integrates and operationalizes the Institutional Development Plan (PDI).

KEYWORDS: Planning. Strategy. Institution. Education. Brazil.

\section{Introdução}

Sabe-se que a implementação eficiente do planejamento estratégico, nos Institutos Federais, contribui para eficácia da gestão e, por conseguinte, proporciona uma prestação de serviços educacionais de qualidade, que tanto necessita o sistema educacional brasileiro.

Para Braga e Monteiro (2005), as questões estratégicas em instituições de ensino precisam ser valorizadas com o avanço da capacidade de gestão, e que atividades rotineiras, burocráticas do dia-a-dia, acabam por tomar todo o tempo do administrador educacional, provocando gargalos e ineficiência administrativa.

Neste contexto, este estudo tem por objetivo identificar e caracterizar a etapa de elaboração do planejamento estratégico do IFB, a partir de percepção da alta gestão e equipe de planejamento, uma vez que o processo estratégico em Instituições de Ensino Superior - IES - é um catalizador do pensamento estratégico que oportuniza não só visão ampla da organização, como também, ferramental adequado de forma a conduzir a ação do gestor para o alcance dos objetivos institucionais (MEYER JR., 2005).

Contudo, há uma discussão na literatura em qual seria a primeira etapa de elaboração do planejamento estratégico: definição de referenciais estratégicos ou diagnóstico 
organizacional. Diante disso, divergem pesquisadores e estudiosos do campo da estratégia quanto à sequência, definição de etapas ou fases do planejamento estratégico. Para Paludo e Procopiuck (2011), a primeira etapa do planejamento estratégico: é a definição de missão, visão e valores, ao passo que para (MARCELINO, 2004; OLIVEIRA, 2009), é o diagnóstico organizacional.

A utilização dessa ou daquela etapa inicial não prejudica o processo de planejamento estratégico, tal como o funcionamento da organização e alcance de resultados. A tomada de decisão sobre a ferramenta de elaboração do planejamento, desse modo, vai depender do nicho de atuação da organização, expertise dos gestores e visão amplificada da estratégia, afirma Oliveira (2009).

Após a introdução e contextualização do tema, ressalta-se que o artigo está organizado de modo a apresentar a metodologia da pesquisa adotada, evidenciando as metodologias, ferramentas e procedimentos na elaboração no Planejamento Estratégico do IFB, observando os pressupostos teóricos da literatura acadêmica, bem como pensamentos dos gestores e servidores diretamente ligados à estratégia organizacional.

\section{Percurso metodológico}

O estudo de caso apresenta uma abordagem qualitativa e é parte integrante de uma dissertação de mestrado, que teve por objetivo identificar os fatores facilitadores e dificultadores na implementação do planejamento estratégico no IFB para o alcance da eficácia organizacional. Desse estudo, permitiu identificar e caracterizar as diversas etapas ou fases, bem como ferramentais e instrumentos empregados no processo.

O locus da pesquisa é Instituto Federal de Brasília e seus respectivos campi. O Instituto é uma organização voltada para o ensino, pesquisa e extensão no âmbito da educação profissional e tecnológica, no âmbito da educação básica ao superior, e também dedicado à formação de professores para rede pública de educação básica que assume valor estratégico no desenvolvimento nacional.

O estudo apoia-se nas técnicas de pesquisa bibliográfica (MARCONI; LAKATOS, 2003) de forma a construir um arcabouço teórico,aliada à entrevista semiestruturada (GASKELL, 2002), como procedimento de levantamento e coleta de dados, por conseguinte, na análise dos dados, a partir da técnica análise de conteúdo. 
A entrevista representa um instrumento básico de coletas de dados (LÜDKE; ANDRÉ, 1986). Assim sendo, optou-se por realizar entrevista semiestruturada, face a face, a partir de um roteiro pré-definido, testado e aprovado, contendo perguntas abertas. Após seleção dos participantes, foi realizado agendamento por e-mail, informando o tema da pesquisa, encaminhando a carta de apresentação dos pesquisadores como autorização do órgão para realização da coleta/produção de dados primários.

Desse modo, foram selecionados para as entrevistas individuais o Reitor, PróReitores, Diretores Gerais e Diretores de Administração e Planejamento nos dez campi. Posteriormente, foram convidados dois setores: a Diretoria de Administração e Diretoria de Orçamento, ambas na Reitoria, a partir da percepção da fala de entrevistados e observação in loco. Desse total, 48,5\% dos respondentes ingressaram no IF - Instituto Federal - no cargo de professor e $51,5 \%$ de técnico administrativos em educação.

Figura 1: Qualificação dos entrevistados

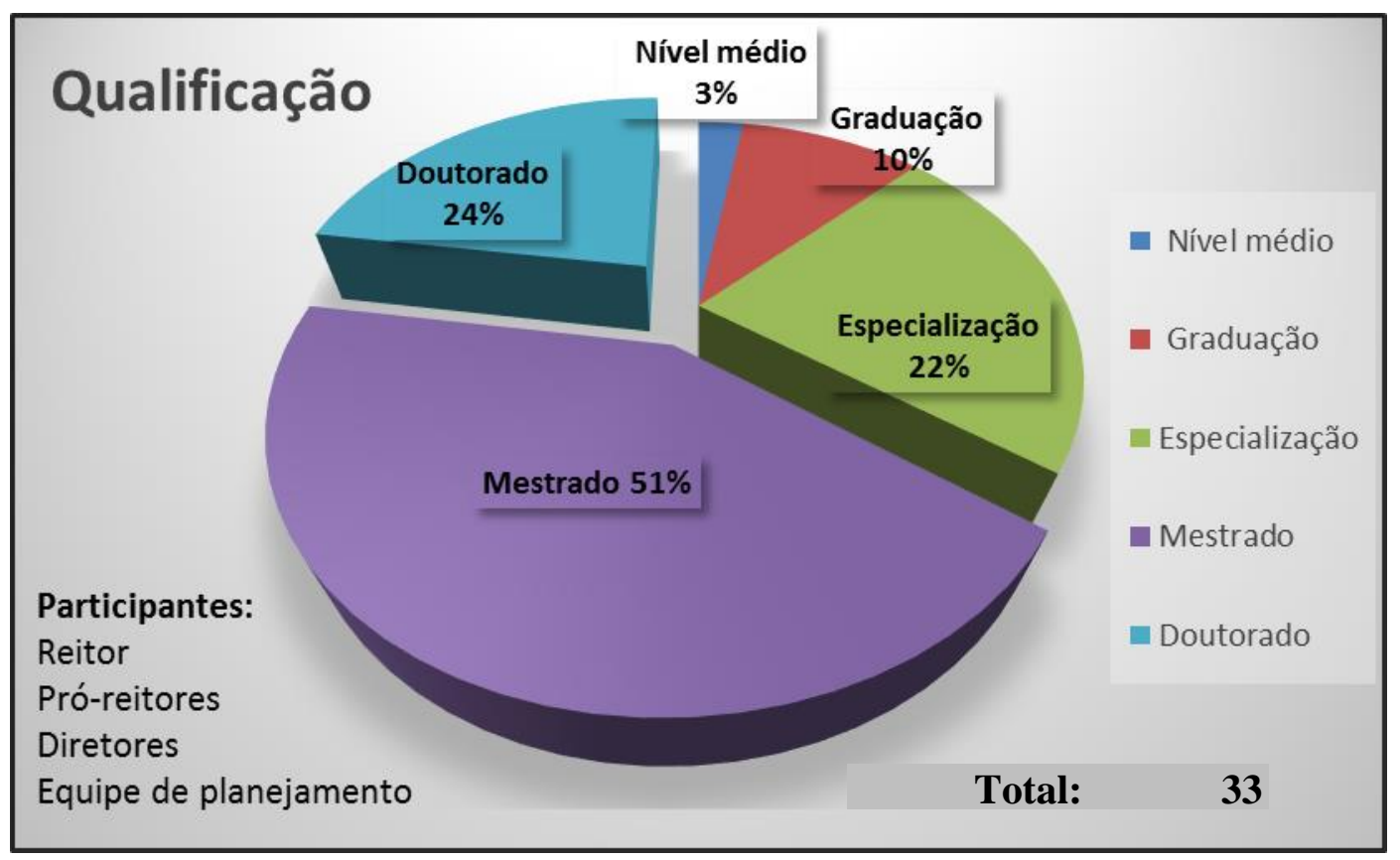

Fonte: Elaboração própria.

Dentre os dados na pesquisa, quanto ao grau de instrução dos participantes, dois pontos chamam atenção: baixo número de gestores e servidores apresenta somente o nível de graduação, por conseguinte, mais de $50 \%$ dos entrevistados são pelo menos mestre. Além disso, perto de $25 \%$ dos entrevistados são doutores. 
No total, foram realizadas trinta e três entrevistas, aplicadas no contexto de cada participante, e percorreu um período de duração de cinco meses. A aplicação do roteiro de entrevista permitiu produzir dados primários no sentido de identificar e caracterizar as diferentes etapas e fases do Planejamento Estratégico do IFB.

Adicionalmente, as conversas foram gravadas, após autorização, por equipamento próprio. As entrevistas transcritas se mostraram material de suma importância para posterior análise de conteúdo. Em média, cada entrevista teve duração de trinta minutos. Como extremos, algumas percorreram perto de uma hora e vinte e três minutos, ao passo que a de menor duração teve onze minutos. Ao final da coleta de dados, o pesquisador contava com cerca de dezessete horas de gravações em áudio para posterior transcrição. Por último, para que as pessoas não identificassem o respondente no texto, foi construído um código iniciado pela letra "E", seguido de numeral.

Quanto à análise de dados, optou-se pela análise de conteúdo do material obtido por meio de entrevista, apoiando-se na literatura pertinente, seguindo o protocolo de Franco (2003), influenciado pelos estudos de Bardin (2006), uma vez que a técnica é utilizada para produzir inferências acerca de dados verbais e simbólicos que possibilitam uma conexão com outras técnicas de pesquisa, sendo assim, um "manual didático e prático para pesquisadores em educação", afirma Franco (2003, p.10).

O processo de construção e classificação da categoria observou a semântica, as semelhanças e diferenças entre enunciados, produzindo comparações, descrições e interpretações, de forma a produzir inferências, subsidiadas pelo referencial teórico sobre o tema planejamento estratégico.

Portanto, a categoria "etapa de elaboração do planejamento estratégico" foi construída, a posteriori, a partir das falas e enunciados dos respondentes, e seu agrupamento observou o valor semântico convergente e divergente das verbalizações, e interpretadas à luz da teoria. A construção de categorias é ponto crucial da análise de conteúdo, na medida em que não existem procedimentos padrão para todos os casos e nem é aconselhável passos apressados e rígidos. Sendo assim, o pesquisador segue seu próprio percurso, fundamentado em seu conhecimento e guiado pela sua competência, ressalta Franco (2003), e certo grau de intuição, criatividade e imaginação (Bardin, 2006).

\section{Definição dos Referenciais Estratégicos se constitui a primeira etapa de elaboração do Planejamento Estratégico no IFB}


A maneira mais adequada para gerenciar as estratégias da organização é por meio do planejamento estratégico. Ferramenta que busca estruturar e ordenar as ideias dos atores envolvidos, orientando o caminho a ser seguido, e define as ações e atividades a serem executadas com vistas a alcançar os objetivos da organização (MATIAS-PEREIRA, 2011).

O planejamento no setor público, além de função técnica, apresenta-se como cumprimento de determinação legal. O Planejamento Estratégico na Administração Pública consiste em um cumprimento constitucional, caracterizado pela responsabilidade e dever político do gestor público, o qual cabe manusear os recursos de forma eficiente e eficaz.

Entretanto, na literatura acadêmica não há consenso em quantas fases ou etapas são necessárias para sua implantação em uma organização, conforme se depreende do quadro 01:

Quadro 01: Fases ou etapas de planejamento estratégico

\begin{tabular}{|c|c|c|c|c|c|c|}
\hline \multicolumn{7}{|c|}{ Planejamento estratégico - Síntese de Fases ou Etapas } \\
\hline \multirow{2}{*}{ Fonte } & \multicolumn{4}{|c|}{ Elaboração } & \multirow{2}{*}{\begin{tabular}{|c|} 
Implementação \\
$5^{\circ}$ Fase
\end{tabular}} & \multirow{2}{*}{$\begin{array}{c}\text { Controle } \\
6^{\circ} \text { Fase }\end{array}$} \\
\hline & $1^{\circ}$ Fase & $2^{\circ}$ Fase & $3^{\circ}$ Fase & $4^{\circ}$ Fase & & \\
\hline $\begin{array}{l}\text { (MATIAS- } \\
\text { PEREIRA, } \\
\text { 2011) }\end{array}$ & $\begin{array}{c}\text { Definição } \\
\text { de } \\
\text { Referencias } \\
\text { Estratégicos }\end{array}$ & $\begin{array}{l}\text { Identificação de } \\
\text { alternativas } \\
\text { estratégicas }\end{array}$ & $\begin{array}{l}\text { Definição } \\
\text { de } \\
\text { Objetivos }\end{array}$ & $\begin{array}{c}\text { Elaboração } \\
\text { de uma } \\
\text { estratégia }\end{array}$ & $\begin{array}{c}\text { Implementação da } \\
\text { estratégia }\end{array}$ & $\begin{array}{l}\text { Controle e } \\
\text { Avaliação }\end{array}$ \\
\hline Fonte & $1^{\circ}$ Etapa & $2^{\circ}$ Etapa & - & $3^{\circ}$ Etapa & $4^{\circ}$ Etapa & $5^{\circ}$ Etapa \\
\hline $\begin{array}{l}\text { (BRAGA e } \\
\text { MONTEIRO, } \\
\text { 2005) }\end{array}$ & $\begin{array}{c}\begin{array}{c}\text { Diagnóstico } \\
\text { (Analise de } \\
\text { Ambiente) }\end{array} \\
\begin{array}{c}\text { Externo e } \\
\text { Interno }\end{array}\end{array}$ & $\begin{array}{c}\begin{array}{c}\text { Estabelecimento } \\
\text { de Diretrizes } \\
\text { Organizacionais }\end{array} \\
\text { Missão, } \\
\text { Visão, } \\
\text { Objetivos, } \\
\text { Valores e } \\
\text { Negócio }\end{array}$ & - & $\begin{array}{c}\text { Formulação } \\
\text { da } \\
\text { Estratégia }\end{array}$ & $\begin{array}{l}\text { Implementação } \\
\text { da Estratégia }\end{array}$ & Controles \\
\hline Fonte & $1^{\circ}$ Etapa & $2^{\circ}$ Etapa & $3^{\circ}$ Etapa & $4^{\circ}$ Etapa & $5^{\circ}$ Etapa & $6^{\circ}$ Etapa \\
\hline $\begin{array}{l}\text { (BRASIL, } \\
\text { PDI } \\
2014 / 2018)\end{array}$ & $\begin{array}{c}\text { Definição: } \\
\text { Missão, } \\
\text { Visão e } \\
\text { Valores }\end{array}$ & $\begin{array}{l}\text { Diagnóstico } \\
\text { organizacional }\end{array}$ & $\begin{array}{l}\text { Objetivo e } \\
\text { Mapa } \\
\text { estratégicos }\end{array}$ & $\begin{array}{c}\text { Definição } \\
\text { de Plano de } \\
\text { Ação ou } \\
\text { Metas }\end{array}$ & $\begin{array}{l}\text { Execução do } \\
\text { Plano }\end{array}$ & $\begin{array}{c}\text { Aferição } \\
\text { da Eficácia } \\
\text { da } \\
\text { Instituição }\end{array}$ \\
\hline
\end{tabular}

Fonte: Elaboração própria.

A etapa inicial acontece na elaboração do planejamento estratégico, passando em seguida pela implementação e controle e avaliação, afirmam (MATIAS-PEREIRA, 2011; BRAGA; MONTEIRO, 2005). Na sua etapa de elaboração do Planejamento Estratégico do IFB, proporcionou-se identificar como se dá este processo, o uso de metodologias e ferramentas, as diretrizes estratégicas e análises de ambiente, bem como mapa, indicadores, objetivos e metas estratégicas. 
É oportuno frisar que existe ampla variedade de modelos de planejamento estratégico que, na sua maioria, reduzem suas etapas ou fases na mesma ideia: aplicação da ferramenta SWOT - Strengths, Weaknesses, Opportunities e Threats; definição de etapas claramente delineadas com pontos de verificação.

$\mathrm{O}$ que distingue o sucesso de qualquer metodologia de gestão estratégica é a capacidade da organização na implantação do plano, por meio de pessoas comprometidas, competência da gestão e foco nos resultados institucionais.

Dessa forma, percebeu-se, inicialmente, que o planejamento no IFB tem como proposta não só responder orientação normativa, mas, também, apresenta-se como função técnica de gestão com a intenção de corrigir falhas no processo, desenvolvendo novos caminhos, de modo a reduzir as incertezas por meio de um processo racional de intervenção na realidade. Assim, apresenta-se não só como mais uma ferramenta de caráter legal, e, sim, como uma visão de futuro e estratégica.

O planejamento na gestão pública ainda é um tema incipiente; afirma o entrevistado E-09 que "é um tema extremamente novo na gestão pública, [...] eu colocaria tranquilamente de dois mil para cá, falar de planejamento [...]", que corrobora com os pensamentos de Paludo e Procopiuck (2011), quando apontam que o planejamento formalmente instituído no setor público é uma visão recente.

De acordo com a entrevista de E-06, "O planejamento é algo fundamental, é a base para que nós possamos atingir alguma meta que foi previamente estabelecida". Todavia, segundo (MINTZBERG, 2004; MINTZBERG, AHLSTRAND, LAMPEL, 2010), explicam que as organizações têm gastando muito tempo e esforço com previsões que dificilmente se concretizarão, já que as mudanças são cada vez mais rápidas e descontínuas.

Por sua vez, o entrevistado E-17 descreve as etapas do planejamento estratégico:

Teoricamente as etapas do planejamento são aquelas, quem você é, onde você quer chegar, a segunda etapa o IFB trabalha, tem estabelecida essa missão no IFB, depois tem a questão da implantação, ele tem a visão e quer saber o que fazer para chegar lá, [...] tem todo um planejamento para chegar[...], isso é estabelecido na questão do PDI.

É no planejamento estratégico da instituição que são definidos os objetivos estratégicos da organização, realizado a análise de ameaças e oportunidades do ambiente externo, dos pontos fortes e fragilidades do ambiente interno, bem como são definidos os referenciais estratégicos, tais como: missão, visão e valores, metas e ações da organização. 
O entrevistado E-18, que trabalha em um campus do IFB, explica que "a primeira etapa envolve as questões relacionadas à elaboração, a gente trabalha aqui com levantamento de cenário identificando o que é primordial, identificando as prioridades para o campus, por meio do diagnóstico".

Portanto, pode-se inferir, a partir das verbalizações e documental, que a etapa inicial do planejamento estratégico no IFB, é a definição de missão e visão, para em seguida realizar o diagnóstico organizacional. A definição da identidade institucional permite responder a uma orientação legal no procedimento elaboração do Plano de Desenvolvimento Institucional - PDI. Neste contexto, afirma a entrevistada E-09 que a “elaboração do PDI por essas instituições de ensino superior, ela coloca ali que tenha um capítulo de planejamento estratégico onde fique evidenciado a missão, a visão da instituição".

\section{Apropriação Institucional da Missão, Visão e Valores pelos atores envolvidos}

No planejamento estratégico do IFB são identificados a missão, visão e valores, que permite informar aos atores internos e comunidade seu "negócio", além de estabelecer objetivos, que se alinhada aos preceitos da transparência pública e gestão participativa. No (BRASIL, PDI, 2014-2018, p. 15-16), são definidos a Missão, Visão e Valores, conforme a seguir:

\section{Missão}

Oferecer ensino, pesquisa e extensão no âmbito da Educação Profissional e Tecnológica, por meio da inovação, produção e difusão de conhecimentos, contribuindo para a formação cidadã o desenvolvimento sustentável, comprometidos com a dignidade humana e a justiça social.

\section{Visão}

Até 2018, consolidar-se no Distrito Federal como instituição pública de Educação Profissional e Tecnológica de qualidade inclusiva e emancipatória, articulada em rede e com a comunidade.

Valores

- Ética;

- Educação como bem público gratuito e de qualidade;

- Formação crítica, emancipatória e cidadã;

-Gestão democrática: transparência, participação, autonomia, pluralismo e integração;

- Respeito à diversidade e à dignidade humana;

- Promoção da inclusão; 
- Inovação;

- Sustentabilidade econômica e socioambiental.

No PDI do IFB, observa-se no trabalho de identificação dos referenciais estratégicos da instituição, que se constitui um ponto essencial de modo a proporcionar sinergias e mobilizar comunidade acadêmica. A missão de uma organização não se trata apenas de uma frase de efeito, destinada a ornamentar salas num cartaz, pelo contrário, procura-se determinar qual o negócio da organização e que tipos de atividades deverão concentrar-se esforços no futuro.

Contudo, na entrevista de E-01, afirma que "A sociedade demanda muito desses institutos [...], e educação é parte da nossa missão, ela é o veículo, e o meio pelo qual a gente faz a transformação, e então a nação como um todo quer mais educação". Tudo isso faz com que "a população cobre resultado, e a população tem pressa".

Por outro lado, quanto à importância desses referenciais, salienta a entrevista de E02: "Percebo que as unidades não têm o mínimo, que seria estampado na sua parede de Missão, Visão e Valores", da mesma forma que, "Muitas pessoas participaram do planejamento estratégico da criação do PDI, mas tem muitos servidores novos, eles não foram, digamos assim, ambientalizados em relação à missão, à visão e aos valores do Instituto com relação ao que ele pretende ser [a visão]”.

Cabe ressaltar que a missão direciona esforços para o alcance dos resultados, enquanto a visão é algo a ser buscado, almejado, é onde se quer chegar. A visão é a chegada do sonho e projeta quem desejamos "ser", que se apresenta em constante mudança, na medida que os resultados são alcançados.

Todavia, os entrevistados reconhecem a importância de se ter uma declaração da identidade institucional, ao mesmo tempo em que apontam fragilidades que podem prejudicar os resultados institucionais. A partir dos enunciados, é possível inferir que na elaboração do planejamento estratégico há necessidade de ambientalizar os servidores com relação à missão, visão e valores; maior envolvimento da comunidade acadêmica; e, que mais servidores deveriam se apropriar da missão institucional.

Por outro lado, a expansão da Rede Federal de Educação Profissional e Tecnologia, de modo acelerado, prejudicou de alguma forma a ambientalização dos servidores quanto à missão, afirma entrevistada E-01, "Se eu cresço muito rapidamente não há tempo de eu incorporar em mim a missão, porque as coisas acontecem primeiro no nível cognitivo, depois elas acontecem no nível operacional”, e declara: 
[...] então esse tempo necessário para a síntese da missão interna corporis eu acho que é o nosso maior desafio hoje, [...] e que todos nós tenhamos a visão clara de como a gente vai responder a sociedade, e aí que o planejamento estratégico se faz realmente necessário, porque quando todos conhecem as demandas, todos sabem onde a gente quer chegar, todos podem somar para a gente chegar lá.

A visão, além de algo a ser alcançado, buscado, almejado, é também uma intenção estratégica que para tanto deve ser clara, mensurável e exequível. A comunidade interna e externa vinculada à organização deve entender e reconhecer seu significado e apoiar sua construção, conforme pondera-se na entrevista E-04: "Se as pessoas não entendem [a Visão], elas não vão se apropriar da ideia".

Por sua vez, os valores desencadeiam comportamentos, propósitos e compromissos (FAIRHOLM, 2009). Um dos valores presentes de forma acentuada na elaboração do PDI e Planejamento Estratégico é a gestão democrática: transparência, participação, autonomia, pluralismo e integração. Assim, o Entrevistado E-12 ressalta:

[...] e tem lá o valor de gestão democrática, que agiria como participativa. E eu vejo muito isso no IFB, o interesse das pessoas em fazer algo coletivamente, pela coletividade, isso é bom. Pode ser ruim em alguns aspectos? Pode! Mas, há um interesse da Instituição em construir alguma coisa, em coletivo, em conjunto.

O senso de valores, propósitos, significados e visão da organização são intrínsecos à eficácia organizacional. Os resultados para serem representativos, ao passo da efetividade, devem constituir-se não somente de medidas quantitativas de sucesso, mas também de ações e medidas qualitativas.

Portanto, planejamento estratégico baseia-se fortemente em conceitos como missão, objetivos e a áreas chaves de resultado de curto e longo prazo e medidas de desempenho, táticas e planos de ação. Esses termos são essenciais para uma boa gestão, mas também não esquecendo de conceitos tais como: valores, compromissos e comportamentos como medidas para a eficácia organizacional.

\section{Da sensibilização ao engajamento da comunidade acadêmica ao planejamento estratégico do IFB}

A sensibilização e participação dos atores é um passo no qual se conquista apoio na construção de um documento que refletirá o significado percebido pelos servidores e

RIAEE - Revista Ibero-Americana de Estudos em Educação, Araraquara, v. 13, n. 1, p. 89-106, jan./mar., $2018 . \quad$ E-ISSN: 1982-5587 
demais colaboradores. De acordo com Paludo e Procopiuck (2011), deve-se construir uma cultura de sensibilização na organização, tal como informa Matias-Pereira (2010), que o envolvimento e sensibilização dos atores promoverão uma maior disposição de modo a debaterem e discutirem, conjuntamente, às soluções dos problemas organizacionais.

A importância percebida pelos servidores e gestores ao envolvimento da comunidade acadêmica no processo é evidenciada na fala da entrevistada E-16 como "essencial". Do mesmo modo, aponta Entrevistado E-18 "é fator mais importante"; por último, Entrevistado E-24 salienta "é uma premissa básica para dar certo, o envolvimento dos servidores e comunidade escolar dentro do processo de planejamento".

As verbalizações evidenciam a importância dada em relação à participação da comunidade acadêmica neste processo, como observado na fala da entrevista E-02 " [...] e daí ter a participação de todo o mundo, e tentar melhorar o que foi feito", bem como do entrevistado E-09: “após esse diagnóstico estratégico, envolveu muitos servidores na instituição".

De acordo como os pensamentos do Entrevistado E-01: “A participação construída a poucas mãos, um projeto construído de gabinete, ele tende a não dar certo". Por outro lado, outro entrevistado conduz uma ideia no sentido de que a participação mais ampla seria mais eficiente, somente em um segundo momento:

[...] eu acho que peca nisso, acho que deveria sentar, levantar os pontos, construir alguma coisa, e daí ter a participação de todo o mundo, e tentar melhorar o que foi feito, e não sentar todo o mundo, todo o instituto para construir um documento, eu acho que peca nisso. (Entrevista E-2).

A participação das pessoas pode proporcionar que o planejamento seja mais eficiente, para a entrevista E-20: "A gente acredita que através do debate, através da troca de experiência das pessoas, da comunidade envolvida, a gente vai ser muito mais assertivo". Paralelamente, é possível notar a importância do envolvimento da comunidade acadêmica, neste ponto, para a eficácia organizacional dentro do processo de planejamento, presente na fala na entrevista de E-18:

O que facilita para nós no cumprimento das metas é o envolvimento de todos na construção das próprias metas [...]. Precisamos que a comunidade escolar entenda isso, docentes, técnicos administrativos e se possíveis alunos. O mais importante é envolver a comunidade escolar no planejamento. [...] senão, colocar as pessoas, sentar as pessoas, discutir o que é planejamento, minimamente estabelecer as metas, em conjunto com as pessoas que vão executar. 
A dinâmica do processo de planejamento no setor público é diferente do setor privado (MATIAS-PEREIRA, 2010, 2011; GOMES, 2013), tal como pontua Rebelo (2004), que as Instituições Públicas de Ensino Superior são organizações que merecem um estudo singular por apresentar características distintas das demais organizações da iniciativa privada, e quanto à participação de pessoas não é diferente, conforme percebe-se na entrevista de E-28: "Sem a participação dos servidores, o planejamento ele pode até ser planejado, mas dificilmente será executado, ainda mais no serviço público onde não a gente há imposição".

Sendo assim, infere-se que, após análise das verbalizações dos servidores e gestores do IFB, fundado na literatura, que a mobilização de pessoas é identificada como um facilitador à implementação do processo de planejamento de forma a estimular pessoas a apropriar-se do planejamento. Para isso, o primeiro passo é desenvolver uma estrutura para mobilizar e aproximar pessoas ao contexto organizacional, que vinculam ao processo de planejamento, por meio da sensibilização, participação e envolvimento, focando na conscientização e comprometimento; além de ser essencial um posicionamento mais assertivo (eficiente) frente às demandas, é uma premissa básica para dar certo que facilita o alcance de metas (eficácia), constituindo, assim, uma peça-chave para o sucesso (efetivo).

Portanto, infere-se que no IFB, os gestores buscam ampliar o engajamento da comunidade acadêmica vinculado ao planejamento, indo aos Campi e unidades, abrindo canais de comunicação, de modo a envolver os alunos, professores e servidores em geral, bem como a comunidade externa (organizações sociais, associações, etc.).

\section{Etapa de elaboração do planejamento estratégico: aplicação da $S W O T$ após Definição dos norteadores estratégicos}

Definidos os referenciais estratégicos, passou-se à análise do diagnóstico organizacional. Para isso, o Instituto fez uso de uma ferramenta conhecida e aplicada nos mais diversos tipos de organização: a SWOT com adaptação para o setor público.

Para elaboração do Planejamento, a partir de verbalizações, revelou-se que participaram mais de 200 membros da comunidade acadêmica do IFB, dentre esses, técnicos, docentes e discentes. Na elaboração do PDI 2014-2018, confirma este esforço da organização em envolver pessoas, e, além disso, contabiliza a entrevistada E-9: 
[...] partiu-se de um diagnóstico estratégico buscando-se identificar sim, no âmbito interno as forças e as fraquezas da instituição, no âmbito externo as oportunidades e as ameaças ao IFB, após esse diagnóstico estratégico envolveu muitos servidores na instituição, aproximadamente 230, 240 servidores participaram cada um nessas etapas desse diagnóstico estratégico em suas Unidades.

O diagnóstico organizacional possibilitou ao IF identificar as forças e fraquezas que são variáveis controláveis, e oportunidades e ameaças que são variáveis incontroláveis. A ferramenta $S W O T$, utilizada para análise ambiental, é instrumental adequado, sendo um dos mais populares quanto ao tema diagnóstico organizacional. Foi implementada no IFB por meio de uma matriz que consolida desde o nível estratégico ao operacional, e utilizada para apoiar a construção do planejamento estratégico e trabalhada em equipe.

Quadro 02: Matrix SWOT IFB

\begin{tabular}{|c|c|c|}
\hline \multicolumn{2}{|r|}{ Ambiente Interno } & Ambiente Externos \\
\hline & FORCAS & OPORTUNIDADES \\
\hline $\begin{array}{l}\mathbf{A} \\
\mathbf{T} \\
\mathbf{O} \\
\mathbf{R} \\
\mathbf{P} \\
\mathbf{O} \\
\mathbf{S} \\
\mathbf{I} \\
\mathbf{T} \\
\mathbf{I} \\
\mathbf{V} \\
\mathbf{O}\end{array}$ & $\begin{array}{l}\text { Qualificação e a qualidade dos cursos } \\
\text { ofertados; } \\
\text { Gestão participativa } \\
\text { Qualificação profissional dos servidores } \\
\text { (professores/TAE); } \\
\text { Qualificação dos servidores; } \\
\text { Forma de ingresso e comprometimento com } \\
\text { o social com a pluralidade e diversidade. }\end{array}$ & $\begin{array}{l}\text { Conjuntura econômica favorável expansão do } \\
\text { mercado de trabalho; } \\
\text { Expansão da rede federal e aumentos dos } \\
\text { investimentos em educação (royalties do petróleo } \\
\text { para a educação); } \\
\text { Demanda crescente por qualificação educacional e } \\
\text { profissionalizante; } \\
\text { Políticas públicas dos IFs em evidência na } \\
\text { sociedade; } \\
\text { Proximidade com o MEC/SETEC e governo Federal }\end{array}$ \\
\hline & FRAQUEZAS & AMEAÇAS \\
\hline $\begin{array}{l}\mathbf{F} \\
\mathbf{A} \\
\mathbf{T} \\
\mathbf{O} \\
\mathbf{R} \\
\mathbf{N} \\
\mathbf{E} \\
\mathbf{G} \\
\mathbf{A} \\
\mathbf{T} \\
\mathbf{I} \\
\mathbf{V} \\
\mathbf{O}\end{array}$ & $\begin{array}{l}\text { Ausência de corpo técnico; } \\
\text { Falta qualificação docente p/ EPT; } \\
\text { Pouca articulação entre ensino, pesquisa e } \\
\text { extensão; } \\
\text { Ausência de Políticas de Gestão de Pessoas; } \\
\text { Falta de revisão da infraestrutura do } \\
\text { Campus após entrega das obras. }\end{array}$ & 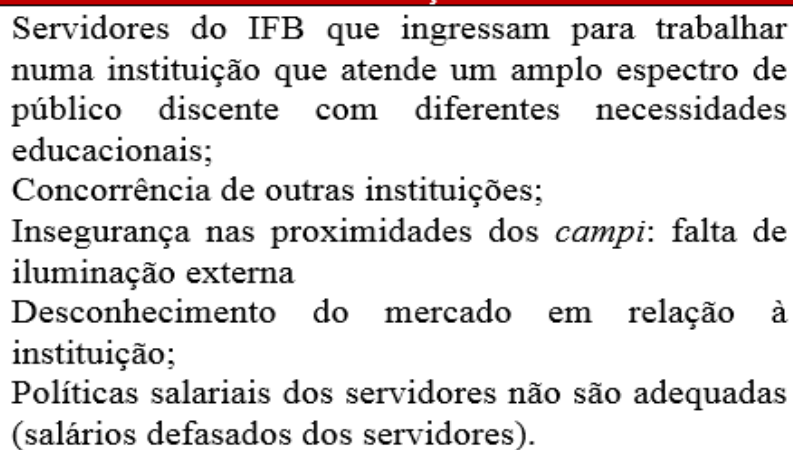 \\
\hline
\end{tabular}

Fonte: Adaptado de (BRASIL, PDI, 2014-2018).

A partir de informações resultantes da aplicação da SWOT, observa-se que a qualificação dos servidores é o item predominante nas forças da organização. No tocante às fraquezas, mais da metade dos itens estão relacionadas ao tema gestões de pessoas. As Oportunidades têm se mostrado como oportunidade de melhorias para os gestores educacionais na instituição. Por último, as ameaças situam temas nas áreas de gestão de 
pessoas, mercado e segurança pública. Desse modo, da informação presente na Matriz SWOT, infere-se que as pessoas se concentram no núcleo central das atenções.

Por último, as revisões do planejamento estratégico podem ser realizadas assim que julgarem necessárias ou modificações ambientais, sendo que o ideal é que seja realizado periodicamente. Entretanto, constata-se que, desde sua vigência, não há evidência ou publicização de atualizações ou revisões no documento inicial do PDI 2014-2018.

Embora, não se consolide com uma etapa ou fase do processo de planejamento estratégico do IFB, a definição dos Fatores Críticos de Sucesso - FCS - foi realizada logo após o diagnóstico, de tal modo que as informações possibilitaram a elaboração dos objetivos, indicadores e metas estratégicas.

\section{Definição dos objetivos estratégicos}

Os Objetivos Estratégicos do IF, levantados a partir do diagnóstico, são os fins a serem perseguidos pela instituição. $\mathrm{Na}$ elaboração dos objetivos estratégicos, vão ao encontro das metas do PDI, construído para que se possa olhar na conclusão dos programas, projetos e ações. O objetivo geral desse esforço buscou desenvolver parâmetros realistas, mensuráveis e exequíveis, focando primeiro na qualidade do ensino, e concomitantemente, pensando em pesquisa e políticas de extensão.

Cabe observar que os objetivos estratégicos devem estar relacionados com a missão da organização, compartilhados e entendidos pelos atores envolvidos. Como os objetivos no setor público não visam obter lucro financeiro, torna-os complexos de serem quantificados, conforme pondera a entrevistada E-01: "O nosso objetivo real, concreto, aquilo que a sociedade espera de nós e cobra de nós é transformação social, então todo o nosso planejamento deve ser em função disso, e para isso que a gente planeja”.

Outro ponto importante que chama a atenção na elaboração dos objetivos no planejamento estratégico conduz para reflexão no sentido de que os objetivos já estão postos em lei. Os objetivos do IFB devem ser os objetivos previstos em Lei, no caso dos IFs, presente no art. 06 e 07 da Lei 11.892 de 2008. Constata-se, portanto, um dificultador na elaboração do planejamento estratégico em Instituições Públicas que ofertam ensino superior no sentido de que como propor objetivos se eles já estão definidos.

Os Objetivos Estratégicos, componentes do Mapa Estratégico do IFB, que se traduzem em declarações de iniciativas, acham-se adotadas pela Instituição para direcionar 
o caminho a ser seguido para o alcance da missão e materialização da visão. Dessa forma, o Planejamento Estratégico adotou os conceitos de Objetivos Estratégicos, que apontam metas claras, de modo a disseminar a estratégia da organização, a partir da teoria de Balanced Scorecard.

Por sua vez, o Mapa (Estratégico) é uma ferramenta simples e eficaz, que traduz de forma visual os objetivos estratégicos que foram considerados pela alta administração e equipe técnica de planejamento. Através de uma figura que ocupa um único ambiente visual foram agrupados os objetivos estratégicos em perspectivas fundamentais.

\section{Considerações finais}

O estudo possibilitou identificar a etapa de elaboração do planejamento estratégico do IFB, caracterizando a construção dos referenciais estratégicos, tal como o diagnóstico organizacional, evidenciando o instrumental empregado, passos e pontos que facilitam e dificultam sua implementação.

Constatou-se que o PDI é o instrumento norteador do planejamento estratégico que necessita ser melhor compreendido pelos gestores e servidores que executam a estratégia da organização de forma a responder à dinâmica e realidade institucional. A elaboração do planejamento estratégico em IFs é um desafio, uma vez que não há consenso, tanto na literatura quanto nos documentos e percepções dos servidores, no estabelecimento de sua primeira etapa: definição dos referenciais estratégicos ou análise de ambiente.

Por outro lado, é evidente o entendimento de que, para a concretização dos referenciais estratégicos, são necessários o envolvimento, engajamento e participação da comunidade acadêmica, de tal forma que as pessoas possam internalizar a missão e visão, de modo a apropriarem-se da ideia, ao tempo que os valores desencadeiam comportamentos, propósitos e compromissos mútuos.

Ademais, mesmo tendo objetivos declarados em lei, o objetivo real, concreto, aquilo que a sociedade espera dos Institutos, em sentido amplo, é transformação social, ao passo que, o objetivo central de tudo isso deve ser focado, em sentido estrito, na construção de uma educação de qualidade.

Portanto, as características predominantes do planejamento estratégico do IFB, compõem-se de uma ferramenta programática de projeção de metas e ações de longo prazo, de cumprimento legal, visto que integra e operacionaliza o PDI, e que mudanças no 
ambiente interno e externo não impulsionam as atualizações revisões e adequações tão necessárias e imprescindíveis quando na utilização da ferramenta SWOT. Uma característica fundamental do planejamento estratégico, que o diferencia do planejamento de longo prazo, é a atenção tempestiva aos fatores ambientais e ações necessárias, de forma a alcançar os objetivos pré-definidos. Logo, ainda que na elaboração do planejamento no IFB, apresentou-se intenções estratégicas, de fato, o que prevalece é o planejamento de longo prazo.

\section{REFERÊNCIAS}

ACKOFF, R.L. Planejamento empresarial. Tradução Marco Túlio de Freitas. Rio de Janeiro: Livros Técnicos e Científicos, 1979.

ALBRECHT, K. Programando o futuro: o trem da linha norte. Tradução Maria Lúcia G. L. Rosa. São Paulo: Editora Makron Books, 1995.

ANGELONI, M.T.; MUSSI, C.C. (org) Estratégias formulação, implementação e avaliação: o desafio das organizações contemporâneas. São Paulo: Saraiva, 2008.

ANSOFF, H. I. Estratégia empresarial. Tradução Antônio Zoratto Sanvicente. São Paulo: McGraw-Hill do Brasil, 1977.

ANSOFF, H. I.; MCDONNELL, E. J. Implantando a administração estratégica. $2^{\mathrm{a}}$ ed. Tradução. Antônio Zorato Sanvicente. São Paulo: Atlas, 1993.

ARAÚJO, M. A. D. Planejamento estratégico: um instrumental à disposição das universidades? Revista de Administração Pública. Rio de Janeiro, FGV, n.30, p. 74-86, jul./ago.1996.

BARDIN, L. Análise de conteúdo. Lisboa: Edições 70, 2006.

BILHIM. Para uma teoria da gestão da mudança estratégica. In: Estratégia e Planeamento na Gestão e Administração Pública. Lisboa: ISCSP, 1995.

BRAGA, R.; MONTEIRO, C. A. Planejamento estratégico sistêmico para instituições de ensino. São Paulo: Hoper, 2005.

BRASIL. Decreto-Lei $\mathbf{n}^{\circ}$ 200, de 25 de fevereiro de 1967. Dispõe sobre a organização da Administração Federal. Disponível em: <http://www.planalto.gov.br/ccivil_03/decretolei/Del0200.htm.>1967. Acessado em: 20 set. 2015.

BRASIL. Plano de Desenvolvimento Institucional: PDI 2014/2018. Instituto Federal de Brasília, IFB. Brasília: IFB, 2014. Aprovado pelo Conselho Superior no dia 20 maio 2014.

RIAEE - Revista Ibero-Americana de Estudos em Educação, Araraquara, v. 13, n. 1, p. 89-106, jan./mar., $2018 . \quad$ E-ISSN: 1982-5587 
<http://www.ifb.edu.br/attachments/article/3933/Plano_de_Desenvolvimento_Institucional _2014_2018_IFB.pdf>. Acesso em: 10 jan. 2016.

BRASIL. Lei $\mathbf{N}^{\circ} \mathbf{1 1 . 8 9 2}$, de 29 de dezembro de 2008, institui a Rede Federal de Educação Profissional, Científica e Tecnológica, cria os Institutos Federais de Educação, Ciência e Tecnologia, e dá outras providências. Disponível em:

<http://www.planalto.gov.br/ccivil_03/_ato2007-2010/2008/lei/111892.htm>. Acessado em: 10 jan. 2016.

CRESWELL, J.W. Projeto de pesquisa: métodos qualitativo, quantitativo e misto.Trad. Luciana de Oliveira da Rocha. Porto Alegre: Artmed, 2007.

FAIRHOLM, M. R. Leadership and Organizational Strategy. The Innovation Journal: The Public-Sector Innovation Journal, Volume 14(1), article 3, p. 1-16, 2009.

FRANCO, M. L. P. B. Análise de conteúdo. Brasília: Plano, 2003.

GASKELL, G. Entrevistas individuais e grupais. In: BAUER, M.; GASKELL, G. Pesquisa qualitativa com texto, imagem e som. Petrópolis: Vozes, 2002. Cap.3.

LÜDKE, M.; ANDRÉ, M. L. Pesquisa em educação: abordagens qualitativas. São Paulo: EPU, 1986.

MARCELINO, G. F. Gestão estratégica de universidade. $1^{a}$ ed. Brasília: Editora UNB, 2004.

MATIAS-PEREIRA, J. Manual de gestão pública contemporânea. $3^{\text {a }}$ ed. São Paulo: Editora Atlas S.A. 2010.

MATIAS-PEREIRA, J. Curso de administração estratégica: foco no planejamento estratégico. São Paulo: Editora Atlas S.A. 2011.

MATIAS-PEREIRA, J. Curso de gestão estratégica na administração pública. São Paulo: Editora Atlas S.A. 2012.

MARCONI, M. A.; LAKATOS, E. M. Fundamentos de metodologia científica. $5^{\text {a }}$ ed. São Paulo: Atlas, 2003.

MATUS, C. Adeus, senhor presidente: governantes governados. São Paulo: Fundap,1996.

MEYER JR., V. Planejamento universitário: ato racional, político ou simbólico: um estudo de universidades brasileiras. Revista Alcance (UNIVALI), Itajaí, v. 12, n. 3. p. 373-389, 2005.

MINTZBERG, $\mathrm{H}$. The fall and rise of strategic planning. Harvard Business Review, $v$. 72, n. 1, p. 107-114, 1994. 
MINTZBERG, H. Ascensão e queda do planejamento estratégico. Porto Alegre: Bookman, 2004.

MINTZBERG, H.; AHLSTRAND, B.; LAMPEL, J. Safári de estratégia: um roteiro pela selva do Planejamento Estratégico. Porto Alegre: Editora Bookman. $2^{\mathrm{a}}$ ed. 2010.

OLIVEIRA, D. P. R. Planejamento estratégico: conceitos, metodologias e práticas. $26^{\mathrm{a}}$ ed. São Paulo: editora Atlas S.A, 2009.

PALUDO, A. V.; PROCOPIUCK, M. Planejamento governamental: referencial teórico, conceitual e prático. São Paulo: Editora Atlas S.A, 2011.

REBELO, L. M. B. A Dinâmica do processo de formação de estratégias de gestão em universidades: a perspectiva da teoria da complexidade. 2004. 278 f. Tese (Doutorado em Engenharia de Produção) -UFSC, Florianópolis, Santa Catarina.

RIZZATTI, G. Etapas do processo da elaboração e implementação do planejamento Estratégico em Universidades. XI Colóquio Internacional Sobre Gestão Universitária na América do Sul: II Congresso Internacional IGLU. Florianopolis, 2011.

STEINER, G. A. Top management planning. New York, The Macmillan Company, 1969.

\section{Como referenciar este artigo}

CAMARGO DIAS, Pedro Henrique Rodrigues de.; COSTA SOUSA, Jonilto.; CAVALCANTE DIAS, Jabson. Um estudo de caso do planejamento estratégico do IFB. Revista Ibero-Americana de Estudos em Educação, Araraquara, v. 13, n. 1, p. 89-106, jan./mar., 2018. E-ISSN: 1982-558.

Submetido em: 08/04/2017

Revisões requeridas: 05/06/2017

Aprovado em: 10/09/2017 